\title{
GYRATE ATROPHY OF THE CHOROID AND RETINA WITH HYPERORNITHINAEMIA, CYSTINURIA AND LYSINURIA
}

\author{
M. Y. KHAN ${ }^{1}$, A. S. IBRAHEIM ${ }^{1}$ and S. FIROOZMAND ${ }^{2}$ \\ Newport
}

\begin{abstract}
SUMMARY
The case of a 45-year-old woman with gyrate atrophy of the choroid and retina is documented. Additional features in this case, to the authors' knowledge not previously described in gyrate atrophy, are massive cystinuria, massive lysinuria, axial hypermetropia and diabetes. Gyrate atrophy is a rare autosomal recessive degenerative disease of the choroid and retina and is accompanied by defective ornithine metabolism. Simell and Takki ${ }^{1}$ demonstrated the association with hyperornithinaemia in 1973. The main metabolic features are those of hyperornithinaemia and ornithuria caused by a deficiency of the mitochondrial matrix enzyme, ornithine aminotransferase (OAT) ${ }^{2-4}$ The responsible human gene has been localised to chromosome $10 .^{5}$ Despite the generalised deficiency of OAT, the literature indicates significant pathological involvement of the eye only. ${ }^{6}$ Ophthalmological features of the disease are myopia (up to 10-20 dioptres), night blindness, constricted visual fields and complicated cataracts. ${ }^{7}$ The clinical picture has been detailed previously by various authors. ${ }^{8.9}$

The case of a 45-year-old woman with gyrate atrophy and hyperornithinaemia is documented here. She has been followed up for 12 years and fully investigated. Additional features in this case, to our knowledge not previously described in gyrate atrophy, are massive cystinuria, massive lysinuria, axial hypermetropia and diabetes.
\end{abstract}

\section{CASE REPORT}

A then 36-year-old Asian woman was first seen in 1982 with a history of night blindness and progressive visual loss of well over 10 years. She had no history of parental consanguinity and one male and three female siblings had no visual problems. The patient has a 24 -year-old son with no visual symptoms or ocular abnormality. She was diag-

From: 'Department of Ophthalmology, St Woolos Hospital, Newport; ${ }^{2}$ Department of Biochemistry, Royal Gwent Hospital, Newport, Gwent, UK.

Correspondence to: M. Y. Khan, FRCOphth, Department of Ophthalmology, St Woolos Hospital, Newport, Gwent NP9 4SZ, UK. nosed a diabetic in 1973 and treated with oral chlorpropamide until 1991 when she became insulin dependent.

On ophthalmological examination her best corrected vision was $6 / 36$ in the right eye with $+1.00 \mathrm{DS}+1.00 \mathrm{DC}$ at $180^{\circ}$ and $6 / 60$ in the left eye with $+1.50 \mathrm{DS}+1.50 \mathrm{DC}$ at $180^{\circ}$. Both eyes had posterior subcapsular cataracts. On fundus examination there were characteristic areas of chorioretinal degeneration described in gyrate atrophy. An electroretinogram was not recordable and colour vision very indefinite. Visual fields were constricted to $5-10^{\circ}$ on Goldmann perimetry with V4e. Dark adaptation was severely impaired. Fluorescein angiography (Fig. 1) shows the characteristic garland-shaped chorioretinal foci of gyrate atrophy. There are large numbers of scattered areas of retinal pigment epithelium transmission defects. Chorioretinal atrophy is so prominent that only large choroidal blood vessels are seen against the whitish background of sclera (Fig. 2).

Serum ornithine was $790 \mu \mathrm{mol} / \mathrm{l}$ on initial presentation. Quantitative analysis of 24 hour urine amino acids (Table I) shows a striking increase in ornithine, cystine and lysine. Systemic pyridoxine (vitamin $B_{6}$ ) therapy was instituted between August 1983 and April 1984 with a starting dose of $100 \mathrm{mg}$ daily increasing to $600 \mathrm{mg}$ daily. There was an initial but short-lived fall in serum ornithine by $40 \%$, but in spite of high doses this was not maintained. The patient was considered a non-responder to pyridoxine.

The patient underwent bilateral cataract extraction ${ }^{10}$ with intraocular lens implants in 1985 (left eye) and 1990 (right eye). Posterior chamber lenses of +25 dioptres were implanted to achieve emmetropia based on biometry. With the patient's prior consent, at the time of cataract extraction aqueous specimens were obtained through the clear cornea using a $30 \mathrm{G}$ hypodermic needle on a tuberculin syringe. Analysis of amino acids in serum, urine and aqueous (Table II) showed raised ornithine in the blood and the aqueous. Whilst the urine showed generalised amino- 


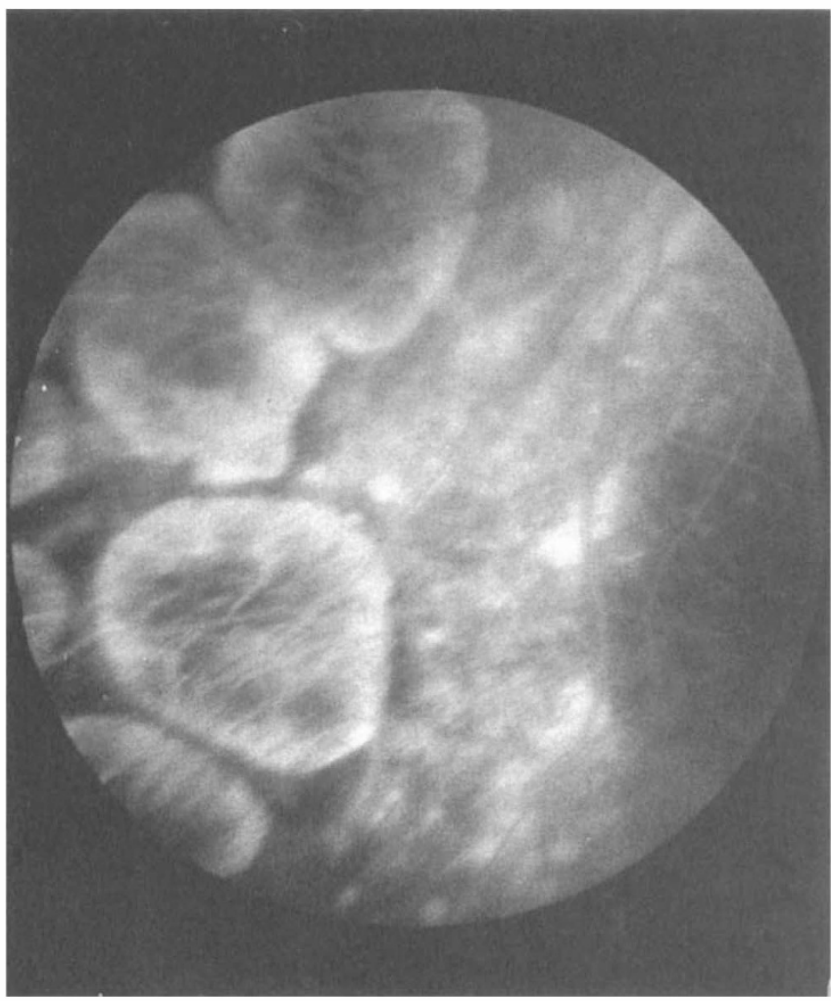

Fig. 1. Late fluorescein angiogram showing the midperiphery of the right fundus. There are characteristic chorioretinal degenerative foci of gyrate atrophy. Additionally, numerous scattered transmission defects are apparent. These are secondary to retinal pigment epithelium atrophy.

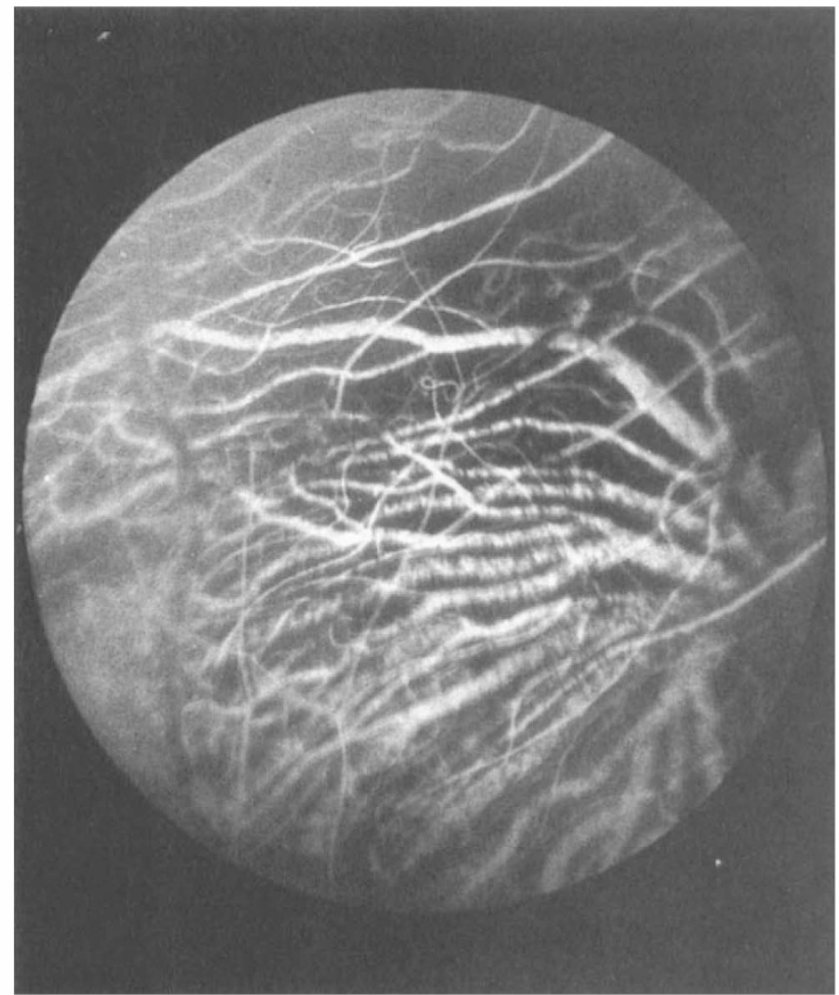

Fig. 2. Fluorescein angiogram showing large choroidal blood vessels against the whitish background of the sclera. These vessels have been unmasked following profound chorioretinal atrophy. aciduria, there was massive ornithinuria, cystinuria and lysinuria. The patient's present best vision is less than $6 / 60$ in each eye. She is managing remarkably well on her present navigational vision.

\section{DISCUSSION}

Jacobson $^{11}$ in 1888 described the first case of gyrate atrophy as atypical retinitis. In 1973 Simell and Takki demonstrated the association of hyperornithinaemia and gyrate atrophy. More than half of the first 200 cases of gyrate atrophy with hyperornithinaemia were reported from Finland, with a smaller number from Japan. ${ }^{12}$ It now appears that the distribution is world wide. Also many atypical cases of gyrate atrophy have been reported with normal or near normal ornithine levels. ${ }^{13}$ It is now generally accepted that demonstration of hyperornithinaemia is a prerequisite in clinical cases of gyrate atrophy for the final diagnosis and a proper classification of the disease. $^{14}$

Gyrate atrophy is unique among the hereditary retinal degenerative diseases in that the underlying biochemical defect is known. Hyperornithinaemia in the cases of gyrate atrophy was demonstrated in $1973^{\prime}$ and deficiency in the mitochondrial enzyme OAT in $1977 . .^{4.15,16}$ The deficiency of OAT activity in the fibroblasts of two patients with gyrate atrophy was shown by immunoassay technique to be due to decreased concentration of the enzyme. ${ }^{17}$ The exact mechanism by which the OAT deficiency and hyperornithinaemia lead to chorioretinal degeneration is not known.

Two clinical subtypes of gyrate atrophy have been described based upon the in vivo or in vitro response to vitamin $\mathrm{B}_{6}$. Pyridoxal phosphate (PLP), a co-enzyme of OATase, administered as pharmacological doses of vitamin $B_{6}$ lowers the ornithine level in a small number of patients. ${ }^{18-20} \quad B_{6}$ responsiveness is manifested by an approximate $50 \%$ reduction in serum ornithine levels and normalisation of serum lysine. Patients responsive to vitamin $B_{6}$ have less severe disease and slow progression, while non-responders to vitamin $\mathrm{B}_{6}$ have severe disease and rapid progression to blindness. Less than $10 \%$ of gyrate atrophy patients reported in the literature are $B_{6}$ responders. ${ }^{13.18 .21}$

OAT is a nuclear-encoded, vitamin- $\mathrm{B}_{6}$-requiring, mitochondrial enzyme that catalyses the interconversion of ornithine, glutamate and proline. ${ }^{22}$ It is the main catabolic enzyme of ornithine and a defect in OAT would result in hyperornithinaemia as seen in gyrate atrophy. Several recent studies have reported on the results of cloning and analysis of the human OAT structural gene (molecular genetic approach). ${ }^{23-26}$ Obligate heterozygotes have one normal active allele of the OAT gene which is responsible

Table I. Quantitative analysis of ornithine, cystine and lysine in the patient's 24 hour urine

\begin{tabular}{ll} 
Ornithine & $7025 \mu \mathrm{mol} / 24$ hours \\
Cystine & $1551 \mu \mathrm{mol} / 24$ hours \\
Lysine & $2780 \mu \mathrm{mol} / 24$ hours \\
\hline
\end{tabular}


Table II. Amino acid contents in the patient's serum, urine and aqueous

\begin{tabular}{lcccccc}
\hline Amino acid & $\begin{array}{c}\text { Serum } \\
(\mu \mathrm{mol} / \mathrm{l})\end{array}$ & \multicolumn{2}{c}{$\begin{array}{c}\text { Urine } \\
(\mu \mathrm{mol} / \mathrm{l})^{\mathrm{a}}\end{array}$} & \multicolumn{2}{c}{$\begin{array}{c}\text { Aqueous } \\
(\mu \mathrm{mol} / \mathrm{l})\end{array}$} \\
\hline Ornithine & 466 & $(62-165)$ & 1187 & $(15-35)$ & 391 & $(23-48)$ \\
Cystine & 14 & $(44-149)$ & 702 & $(0-68)$ & 28 & $(6-31)$ \\
Lysine & 98 & $(99-242)$ & 587 & $(0-35)$ & 75 & $(88-156)$ \\
Aspartic acid & 42 & $(18-33)$ & 50 & $(8-45)$ & 16 & $(5-10)$ \\
Serine & 191 & $(54-191)$ & 158 & $(11-64)$ & 208 & $(44-190)$ \\
Arginine & 69 & $(57-117)$ & 93 & $(0-23)$ & 90 & $(67-129)$ \\
Threonine & 129 & $(76-135)$ & 53 & $(2-14)$ & 146 & $(47-144)$ \\
Glutamine & 402 & $(424-846)$ & 157 & $(7-64)$ & 808 & $(521-814)$ \\
Tyrosine & 51 & $(36-84)$ & 44 & $(2.6-23)$ & 86 & $(57-109)$ \\
Phenylalanine & 76 & $(49-97)$ & 26 & $(0-10.2)$ & 92 & $(62-125)$ \\
\hline
\end{tabular}

Values in parentheses are the reference range.

"Urinary amino acids are expressed in $\mu \mathrm{mol} / \mathrm{mmol}$ creatinine.

for $50 \%$ of the total OAT mRNA and enzyme activity in a cell, in agreement with the autosomal recessive pattern previously observed. ${ }^{4.15 .16}$ Most of the cases of gyrate atrophy examined at the molecular level have shown grossly intact OAT genes and mRNAs. In 1988 Ramesh et al. ${ }^{24}$ cloned and sequenced cDNAs for OATase from one $\mathrm{B}_{6}$-responsive and one non- $\mathrm{B}_{6}$-responsive gyrate atrophy patient. They concluded that in both cases there was a different single point mutation predicting a single amino acid change in the mature protein. This indicates that the two forms of gyrate atrophy represent different allelic mutants of the same gene. It is likely that a complete lack of OAT gene expression represents those cases that have no OAT activity and non-responsiveness to vitamin $B_{6}$ therapy. Expression of the OAT gene and synthesis of a decreased amount of OAT protein shows residual activity (up to $19 \%$ ) and responsiveness to vitamin $\mathrm{B}_{6}$ therapy. ${ }^{26}$ Many patients with gyrate atrophy are compound heterozygotes, reflecting the molecular heterogenicity of this disease. ${ }^{26}$ This in turn is reflected in its well-documented clinical heterogenicity. ${ }^{13}$ Identification of gyrate atrophy patients who are responsive to $\mathrm{B}_{6}$ therapy is important, since treatment may lead to improved visual function. ${ }^{27}$

In clinical practice it is usually the onset of myopia that leads to the first consultation and a definitive diagnosis made in childhood or the early teens. The patient presented above was born in the Indian subcontinent. She shows the ophthalmic, biochemical and genetic characteristics of typical gyrate atrophy associated with hyperornithinaemia. As opposed to cases reported in the literature of mild to high myopia, she is hypermetropic. This suggests that myopia is not a constant feature in gyrate atrophy. This case also demonstrates strikingly high levels of urinary cystine and lysine. Some increase in the levels of these two amino acids is expected with high levels of ornithine, as these di-basic amino acids share the same renal transport mechanism. We have been unable to find any reference to an increase of this magnitude and she is considered to be at risk from cystine stone formation in the urinary tract. A recent intravenous pyelogram has been reported as normal. This case of gyrate atrophy supports additional information of renal tubular dysfunction. Association of diabetes with gyrate atrophy has not been identified before. It remains to be established whether these metabolic disorders are related in any specific way. A diabetic for 20 years, this patient shows no evidence of retinopathy whatsoever. In view of the extensive chorioretinal atrophy one would expect this protection, as the metabolic needs of the retina are reduced. It is assumed that the effect has a similar mechanism to that of panretinal photocoagulation. ${ }^{25}$

The authors would like to express their grateful thanks to $\mathrm{Mr}$ Graham Titley, Medical Librarian, Postgraduate Centre, Newport Hospitals, for his immense help with the literature search, and to Mr Nigel Pearce, Chief Photographer, Medical Illustration Department. Royal Gwent and St Woolos Hospitals, for his help with the photographic illustrations.

Key words: Axial hypermetropia, Cystinuria, Gyrate atrophy, Hyperornithinaemia, Vitamin B

\section{REFERENCES}

1. Simell O, Takki K. Raised plasma-ornithine and gyrate atrophy of the choroid and retina. Lancet 1973;1:1031-3.

2. Sengers RCA. Trijbels JMF, Brussaart JH, Deutman AF. Gyrate atrophy of the choroid and retina and ornithineketoacid amino transferase deficiency. Pediatr Res 1976:10:894.

3. O’Donnell JJ. Sandman RP, Martin SR. Gyrate atrophy of the retina: inborn error of L-ornithine:2-oxoacid aminotransferase. Science 1978;200:200-1.

4. Valle D, Kaiser-Kupfer MI, Del Valle LA. Gyrate atrophy of the choroid and retina: deficiency of ornithine aminotransferase in transformed lymphocytes. Proc Natl Acad Sci USA 1977:74:5159-61.

5. O`Donnell JJ, Vannas-Sulonen K. Shows T, Cox D. Ornithine aminotransferase maps to human chromosome 10 and mouse chromosome 7. Cytogenet Cell Genet 1985;40: 716A.

6. Valle D, Simell O. The hyperornithinemias: gyrate atrophy of the choroid and retina. In: Stanbury JB, Wyngaarden JB, Frederickson DS, Goldstein JL. Brown MS (eds) The metabolic basis of inherited disease. 5 th ed. New York: McGrawHill, 1983:382-401.

7. Kaiser-Kupfer MI, Kuwabara T, Uga S, Takki K, Valle D. Cataract in gyrate atrophy: clinical and morphologic studies. Invest Ophthalmol Vis Sci 1983:24:432-6.

8. Takki K, Simell O. Gyrate atrophy of the choroid and retina with hyperornithinemia. Birth Defects 1976;12:373-84.

9. Vannas-Sulonen K. Sipila I, Vannas A. Simell O, Rapola J. Gyrate atrophy of the choroid and retina: a five year follow up of creatine supplementation. Ophthalmology 1985;92: 1719-27.

10. Takki KK, Milton RC. The natural history of gyrate atrophy of the choroid and retina. Ophthalmology 1981;88:292.

11. Jacobson E. Ein Fall von Retinitis Pigmentosa atypica. Klin Monatsbl Augenheilkd 1888;26:202-6.

12. Takkahashi O, Hayasaka S, Kiyosawa M, Mizuno K, Saito T, Tada K, Igarashi Y. Gyrate atrophy of choroid and retina complicated by vitreous haemorrhage. Jpn J Ophthalmol 1985;29:170-6.

13. Kaiser-Kupfer MI, Valle D, Bron A. Clinical and biochemical heterogeneity in gyrate atrophy. Am J Ophthalmol 1980;89:219.

14. Bargum R. Differential diagnosis of normoornithine gyrate atrophy of the choroid and retina. Acta Ophthalmol (Copenh) 1986:64:369-73.

15. Trijbels JMF, Sengers RCA. Bakkeren JAJM, Dekort AFM, Deutman AF. L-Ornithine-ketoacid-transaminase deficiency in cultured fibroblasts of a patient with hyperornithinemia 
and gyrate atrophy of the choroid and retina. Clin Chim Acta 1977;79:371-7.

16. O'Donnell JJ, Sandman RP, Martin SR. Deficient L-ornithine:2-oxoacid aminotransferase activity in cultured fibroblasts from a patient with gyrate atrophy of the retina. Biochem Biophys Res Commun 1977;79:396-9.

17. Ohura T, Kominami E, Tada K, Katunuma N. Gyrate atrophy of the choroid and retina: decreased ornithine aminotransferase concentration in cultured skin fibroblasts from patients. Clin Chim Acta 1984;136:29-37.

18. Shih VE, Berson EL, Mandell R, Schmidt SY. Ornithine ketoacid transaminase deficiency in gyrate atrophy of the choroid and retina. Am J Hum Genet 1978;30:174-9.

19. Berson EL, Schmidt SY, Shih VE. Ocular and biochemical abnormalities in gyrate atrophy of the choroid and retina. Ophthalmology 1978;85:1018-27.

20. Kennaway NG, Weleber RG, Buist RM. Gyrate atrophy of the choroid and retina with hyperornithinemia: biochemical and histologic studies and response to vitamin $\mathrm{B}_{6}$. Am $\mathrm{J}$ Hum Genet 1980;32:529-41.

21. Hayasaka S, Saito T, Nakajima Y, Takaku T, Shiono T, Mizuno K, Ohmura K, Tada K. Gyrate atrophy with hyperornithinaemia: different types of responsiveness to vitamin $\mathrm{B}_{6}$. Br J Ophthalmol 1981;65:478-83.
22. Peraino C, Pitot HC. Ornithine- $\delta$-transaminase in the rat: immunoassay and some general properties. Biochim Biophys Acta 1963;73:222-31.

23. Mitchell GA, Brody LC, Looney J, Steel G, Suchanek M, Dowling $C$, et al. An initiator codon mutation in ornithine- $\delta$ aminotransferase causing gyrate atrophy of the choroid and retina. J Clin Invest 1988;81:630-3.

24. Ramesh V, McClatchey AI, Ramesh N, Benoit LA, Berson EL, Shih VE, Gusella JF. Molecular basis of ornithine aminotransferase deficiency in $\mathrm{B}_{6}$-responsive and non-responsive form of gyrate atrophy. Proc Natl Acad Sci USA 1988;85:3777-80

25. Inana G, Hotta Y, Zintz C, Takki K, Weleber RG, Kennaway NG, et al. Expression defect of ornithine aminotransferase gene in gyrate atrophy. Invest Ophthalmol Vis Sci 1988;29:1001-5.

26. Inana G, Hotta Y, Zintz C, Chambers C, Kennaway NG, Weleber RG, et al. Molecular basis of ornithine aminotransferase defect in gyrate atrophy. Prog Clin Biol Res 1991;362:191-219.

27. Weleber RG, Kennaway NG. Clinical trial of vitamin $B_{6}$ for gyrate atrophy of choroid and retina. Ophthamology 1981;88:316-24.

28. Ulbig MRW, Hamilton AMP. Factors influencing the natural history of diabetic retinopathy. Eye 1993;7:242-9. 